\title{
Tesis dels cursos 2010-11 i 2011-12
}

Doctorand/a: Camino Vallhonrat, Xavier

Titol: Estudio Cultural del skateboarding en Barcelona (1975-2010)

Any: 03/05/2012 | Universitat: URV

Direcció: Pujadas, Joan Josep/ Maza Gutiérrez, Gaspar

Consulta: http://hdl.handle.net/10803/81714

Doctorand/a: Otero García, Laura

Titol: Campos de soledad. Atención primaria y procesos asistenciales en pueblos de Segovia.

Any: 16/02/2012 | Universitat: URV

Direcció: Comelles, Josep Maria

Consulta: http://hdl.handle.net/10803/79147

Doctorand/a: Ortega Senet, Belén

Titol: Jóvenes y poder local en el "proceso de cambio" boliviano (2008-2010). Reflexiones sobre la agencia de jóvenes participantes del taller de formación politica del proyecto de poder local en el Alto, Bolivia.

Any: 20/01/2012 | Universitat: URV

Direcció: Romaní Alfonso, Oriol / Gimeno Martín, Juan Carlos

Consulta: http://hdl.handle.net/10803/77856

Doctorand/a: AnziL, Flavia Veronica

Titol: "Si yo cerrara los ojos y la tuviera delante, o sea, sin mirarla... seria una niña totalmente española, catalana, de aqui". Representaciones, identidades, filiaciones en la adopción internacional en Cataluña.

Any: 16/01/2012 | Universitat: URV

Direcció: Roca i Girona, Jordi / Bodoque Puerta, Yolanda

Consulta: http://hdl.handle.net/10803/73969 
Doctorand/a: Paz Reverol, Carmen Laura

Titol: Padecimientos y tratamientos en torno al alcohol: representaciones y prácticas Any: 09/11/2011 | Universitat: URV

Direcció: Romaní Alfonso, Oriol

Consulta: http://hdl.handle.net/10803/51763

Doctorand/a: Sepúlveda Galeas, Mauricio

Titol: El riesgo como dispositivo de gobierno en el campo de las drogas: Exotización, vicio y enfermedad

Any: 24/10/2011 | Universitat: URV

Direcció: Romaní, Oriol

Consulta: http://hdl.handle.net/10803/69361

Doctorand/a: Lolicato, Andrea

Titol: Movilidad transnacional y movimientos sociales: las organizaciones solidarias de argentinos en Roma y Barcelona.

Any: 21/09/2011 | Universitat: URV

Direcció: Pujadas Muñoz, Joan Josep

Consulta: http://hdl.handle.net/10803/38878

Doctorand/a: González Granados, Paula

Titol: Tú mira la foto, pero no se la enseñes a nadie. Análisis de la práctica fotográfica, los discursos y las representaciones de niños $y$ adolescentes en el contexto de talleres de fotografía participativa. Dos estudios de caso.

Any: 15/09/2011 | Universitat: URV

Direcció: Prat Carós, Joan / Grau Rebollo, Jordi

Consulta: http://hdl.handle.net/10803/51883

Doctorand/a: Alonso Cambrón, Miguel

Titol: Sociofonía, identidad y conflicto. La "vida sonora" de la Part Alta.

Any: 11/07/2011 | Universitat: URV

Direcció: Pujadas Muñoz, Joan Josep

Consulta: http://tesisenred.net/handle/10803/42585 
Doctorand/a: Casadó Marín, Lina Cristina

Titol: Los discursos del cuerpo y la experiencia del padecimiento. Acciones autolesivas corporales en jóvenes.

Any: 29/06/2011 | Universitat: URV

Direcció: Gracia Arnaiz, Mabel / Roca Girona, Jordi

Consulta: http://www.tdx.cat/handle/10803/37364

\section{Doctorand/a: Rodríguez Goia, Marisol}

Titol: Mundos urbanos: el contacto con el "otro" y la producción de la diferencia en la ciudad.

Any: 09/06/2011 | Universitat: URV

Direcció: Roca Girona, Jordi / Goldenberg, Miriam

Consulta: http://www.tdx.cat/handle/10803/37345

Doctorand/a: Verdugo Córdova, Joel Alfonso

Titol: Los documentos personales como herramientas analiticas en el estudio de los movimientos sociales: El caso de la Universidad de Sonora (México)

Any: 12/04/2011 | Universitat: URV

Direcció: Pujadas Muñoz, Joan Josep

Consulta: http://hdl.handle.net/10803/34767

Doctorand/a: Andreu Tomàs, Agustí

Titol: De la lògica de la cultura a la logica del producte. Les activacions econòmiques del patrimoni, la redefinició dels museus d'etnologia i l'emergencia de nous patrimonis

Any: 18/02/2011 | Universitat: URV

Direcció: Prat, Joan / Pujadas, Joan Josep

Doctorand/a: Mariath Belloc, Márcio

Titol: Homem-sem-história. A narrativa como criaçao de cidadania

Any: 15/02/2011 | Universitat: URV

Direcció: Martínez Hernáez, Àngel

Consulta: http://hdl.handle.net/10803/32220 
Doctorand/a: Veiga Cabral, Károl

Titol: Artesaos da saúde: Saúde mental e participaçao social em Porto Alegre Any: 14/02/2011 | Universitat: URV

Direcció: Martínez Hernáez, Àngel

Consulta: http://hdl.handle.net/10803/32218

Doctorand/a: García Moreno, Cristina

Titol: Mujeres migrantes cubanas: "resolviendo" e "inventando" también en España Any: 01/02/2011 | Universitat: URV

Direcció: Pujadas, Joan Josep

Consulta: http://hdl.handle.net/10803/84128

Doctorand/a: Bernal Solano, Mariola

Titol: Cuerpo, comida y migraciones. Un análisis transcultural de los (mal)estares alimentarios

Any: 22/12/2010 | Universitat: URV

Direcció: Gracia, Mabel / Comelles, Josep Maria

Consulta: http //hdl.handle.net/10803/34759

Doctorand/a: Duch Plana, Josep M.

Titol: Assaig sobre l'axiología hindú, els quatre purusârthes. La resposta bindú a la qüestió kantiana de què podem esperar de la vida

Any:21/12/2010 | Universitat: URV

Direcció: Prat, Joan

Consulta: http://hdl.handle.net/10803/32217

Doctorand/a: Silva Trad, Sergio do Nascimento

Titol: A trajetória da prevenção às drogas no Brasil: do proibicionismo à redução de danos e seus reflexos nas politicas locais

Any: 20/12/2010 | Universitat: URV

Direcció: Romaní Alfonso, Oriol

Consulta: http://hdl.handle.net/10803/34577 
Doctorand/a: Hurtado García, Inmaculada

Titol: More to life. Envejecimiento, salud y cuidados en la migración internacional de retiro en la Costa Blanca (Alicante) Any: 29/06/2010 | Universitat: URV

Direcció: Comelles Esteban, Josep Maria / Esteban Galarza, Mari Luz

Doctorand/a: Antonín Martín, Montserrat

Titol: La mediación intercultural en el sistema de salud de Cataluña

Any: 30/04/10 | Universitat: URV

Direcció: Comelles Esteban, Josep Maria

Consulta: http://www.tdx.cat/handle/10803/8442

Doctorand/a: Correa Urquiza, Martín

Titol: Radio Nikosia: la rebelión de los saberes profanos (otras prácticas, otros territorios para la locura

Any: 30/04/10 | Universitat: URV

Direcció: Martínez Hernáez, Ángel

Consulta: http://www.tdx.cat/handle/10803/8437 